\title{
Non-starch polysaccharide intakes in Mexican villagers and residents of Mexico City
}

\author{
BY CLAUDIA P. SANCHEZ-CASTILLO ${ }^{1}$, DAVID GRUBB ${ }^{2}$, MARIA DE LOURDES \\ SOLANO $^{1}$, MICHAEL F. FRANKLIN ${ }^{3}$ AND W. PHILIP T. JAMES ${ }^{2}$ \\ ${ }^{1}$ Instituto Nacional de la Nutrición Salvador Zubirán (INNSZ), Subdirección de Nutrición \\ Experimental y Ciencia de los Alimentos, Departamento de Fisiología de la Nutricion, México 14000, DF \\ ${ }^{2}$ The Rowett Research Institute, Bucksburn, Aberdeen AB21 9SB \\ ${ }^{3}$ Biomathematics and Statistics Scotland (BioSS), c/o Rowett Research Institute, Bucksburn, Aberdeen
} $A B 219 S B$

(Received 3 August 1995 - Revised 26 April 1996 - Accepted 3 July 1996)

\begin{abstract}
A study was performed in a rural Mexican community and in Mexico City to investigate possible differences in non-starch polysaccharide (NSP) intakes. One hundred and fourteen women (fifty-five rural and fifty-nine urban) and forty-three men (twenty-four rural and nineteen urban) completed $24 \mathrm{~h}$ recall questionnaires for three consecutive days with NSP intakes being estimated from a specially prepared set of new food composition tables. Potential underestimation of intakes was assessed by estimating individual BMR and dividing the estimated energy intakes by BMR to give a ratio. Excluding severe underrecording (ratio <1.01) suggested NSP intakes of 21.8 and $17.3 \mathrm{~g} / \mathrm{d}$ in rural men and women and 17.7 and $15.6 \mathrm{~g} / \mathrm{d}$ in urban men and women respectively. NSP sources differed, with a marked fall in intake from pulses in the urban areas but a compensatory increase of tortilla intakes and a rise in NSP-rich fruit consumption. Both soluble- and insoluble-NSP intakes were higher in rural areas. NSP intakes scaled by probable energy intakes of moderately active adults in developing countries suggest that NSP intakes in Mexico are similar to adjusted values in Africa, i.e. $26.9 \mathrm{~g} / \mathrm{d}$ in Mexico $v .28 .5 \mathrm{~g} / \mathrm{d}$ in Africa in rural men and $22.9 v .21 .0 \mathrm{~g} / \mathrm{d}$ respectively in rural women. The NSP : energy density ratio $(\mathrm{g} / \mathrm{MJ})$ of the rural diet conformed with the World Health Organization (1990) goal. Data available on urban and rural communities for three countries showed that in each case the intake of NSP was lowest in the urban community.
\end{abstract}

Non-starch polysaccharide intakes: Dietary fibre: Adults

The importance for health of adequate NSP intakes is becoming widely accepted by national committees concerned with public health in the Western world. Analyses have been made, for example, of the possible effects of diets low in NSP on the incidence of metabolic diseases such as overweight and obesity (Weinsier et al. 1982; Garrow, 1988), diabetes (Goulder et al. 1978; Vinik \& Jenkins, 1978; Jenkins, 1988), coronary heart disease (Morris et al. 1977; Kromhout et al. 1982; Kushi et al. 1985), gallstones (Heaton et al. 1993) and large-bowel cancer (Willett, 1989; Cummings et al. 1992). Such issues are of particular importance in Mexico because the proportion of deaths from non-communicable diseases has substantially increased in recent years (Bobadilla et al. 1993). There is also concern amongst the medical profession about the increases in national rates of both large bowel cancer (Villalobos et al. 1990) and coronary heart disease (Secretaría de Salud, 1991), and in most developing countries this has been seen particularly in urban communities (Sánchez-Castillo et al. 1994a). 
During the past 50 years Mexico has undergone major economic and social change with associated changes in the food chain as local industrial production of new foods increases. The nutritional transition is amplified by the compositional differences between processed foods and traditional foods. Tortillas, for example, are now produced both industrially and by customary cooking and baking methods at home or at small market stalls. The importation of new food products, e.g. ready-made foods mainly from the USA, is also having an impact. These trends in food processing and food imports, with the support of mass media advertising, are thought to be changing typical food habits.

The traditional Mexican diet, based on maize and beans, has been assumed to have a high NSP content. However, the original proposition on the importance of fibre-rich foods (Burkitt, 1971, 1972) was not based on reliable data for the NSP content of foods from the developing world and there are still no data on NSP intakes in any Latin-American country. NSP intakes used not to be of serious concern in Mexico but they are assuming greater importance as consumers are persuaded by advertising to consume special processed 'fibrerich products' to maintain health. These new products appear to have no more NSP than the traditional foods. Recently Sánchez-Castillo et al. $(1994 c, 1995)$ published analyses of the NSP in Mexican pulses, cereal products, fruits and vegetables which allow a more detailed analysis of the Mexican diet in transition.

The impact of industrially produced foods is greatest in cities but it is not known how much NSP intakes differ between those consuming a typical urban diet and those consuming traditional diets. An assessment of NSP intakes and sources was therefore made both in a rural setting and in Mexico City. The rural area, inhabited by a traditional peasant society, is believed to have escaped most of the advertising media's influence and inhabitants have greater difficulties in purchasing new food products. The area has kept to its food traditions with maize and beans remaining central to the diet and with only modest intakes of industrially manufactured foods. Inhabitants also have direct access to locally produced vegetables and fruit. Mexico City was chosen as the other site because there the impact of the lay press and of advertising is considered to be at its most extreme (SánchezCastillo et al. 1989).

The objective of the present study was to investigate urban-rural differences in NSP intake as a possible contributor to the development of those chronic diseases seen in urban dwellers (Sanchez-Castillo et al. 1994a).

\section{SUBJECTS AND METHODS}

\section{Selection and recruitment of subjects}

Rural area. The study was conducted in Malinalco, a small town $200 \mathrm{~km}$ south west from Mexico City at an altitude of $2660 \mathrm{~m}$. It has a health centre, run by the National Institute of Nutrition (INNSZ), which helped to facilitate the survey and ensured both good communication with the population and a high compliance rate from the volunteers. The study was undertaken during February and March 1991, a hot period of the year when the average temperature is $25^{\circ}$. A random sample of 100 adults between the ages of 20 and 64 years was selected from the health centre register which covered the eight 'barrios' or districts of the town. Those selected were invited to attend a meeting at which the study was explained; a total of seventy-eight (twenty-three men and fifty-five women) agreed to participate.

Urban area. The urban study was conducted in the Tlalpan District of Mexico City. Considered one of the most densely populated cities in the world, Mexico City is built on a plateau approximately $2200 \mathrm{~m}$ above sea level. The study was undertaken between March 
and May 1992, when the average temperature is about $20^{\circ}$. From a randomly selected list of 100 adults on the health centre register for the whole district, seventy-six volunteers, nineteen men and fifty-seven women aged between 20 and 64 years were obtained.

\section{Study design}

The volunteers were fully informed about the nature of the project, which had been approved by the Ethical Committee of the INNSZ. The aim of the study was explained in detail to the volunteers who then agreed to their food intake being assessed over three successive days. The day before the study began they were visited at home and asked to complete a general questionnaire. To provide background information, their weights, heights and skinfolds were measured at the health centres by the same observer throughout. Height was measured with a Microtoise (CMS Weighing Equipment Ltd, London); weight was measured in light clothes but without shoes on a Toledo scale, model 2181 (MettlerToledo, Colonia Atlampa, Mexico). A Lange Skinfold caliper (Cambridge Scientific Industries, Cambridge, MD, USA) was used for the skinfold measurements and body fat was estimated from the sum of four skinfolds (biceps, triceps, subscapular and suprailiac) using the method of Durnin \& Womersley (1974).

\section{Collection of food data in rural and urban Mexico}

Three successive daily assessments of food eaten in the previous $24 \mathrm{~h}$ were made through interview. At both centres the clinics were open $7 \mathrm{~d}$ per week and subjects were interviewed when convenient. In effect the 3 days assessed can be considered as a random set of three successive days. The differences between weekend and weekday diets are believed to be small and there was no difference in the pattern of attendance days between the two groups. Thus, it is reasonable to accept all group means as representing an average over $7 \mathrm{~d}$. The recall method for assessing the food quantities consumed was simplified by comparing them with local household measures. The volumes of different sized cups, 'jarros', bowls, glasses and spoons were obtained by determining the weight of water contained in a full vessel. The volumes of the various local popular drinks, e.g. atole, coffee etc., were converted to weights by using appropriate density factors. Locally produced foods, such as tortillas and bread bought in the local weekly market or 'tianguis', were sampled to obtain their average weights. Other items, including those for which single items may differ in size, such as eggs or fruit, were sampled in order to obtain an average weight. Similarly, processed foods were sampled to check the weight of the packaged food.

Two fieldworkers were used, one at each centre. Each had a thorough knowledge of the food habits and of the commonly eaten foods in their study area. They also followed a standardized protocol for the collection of data and were trained to monitor the volunteers' food intake with minimum interference. Interviews for repeated dietary assessments were held at a fixed time of day either in the volunteers' place of work or in their home.

\section{The coding of dietary records: conversion into energy and fibre intakes}

A combination of direct analysis and food composition tables was used to form estimates of energy and NSP intakes from estimates of consumption of up to 293 distinct food items. The energy values of food quoted in the Mexican food composition tables (Hernandez et al. 1980) were used to calculate energy intakes. For some manufactured foods and beverages where no local data were available, the energy values were based on comparable foods and drinks in the British food tables (Holland et al. 1991a,b,c). The NSP content of 
foods was assessed by direct analysis (Sánchez-Castillo et al. 1994a, 1995) due to the absence, for Mexican foods, of information based on modern analytical techniques (Sánchez-Castillo et al. 1994b). The food samples chosen for analysis were representative of those consumed by the local population.

For a few foods Mexican NSP values were not available so estimates were taken from British food composition tables (Holland et al. 1991a,b,c) or published literature (Englyst et al. 1988, 1989; Hudson \& Englyst, 1995). When no data were available for a food the fibre content was estimated by reference to another food within the same group. Once the food data had been collected, the information recorded on the survey forms was checked carefully, coded and entered into a computer database. The nutritional intakes were calculated using software developed at the Rowett Research Institute, Aberdeen. This software is based on the Oracle Relational Database Management System and uses data from the UK National Nutrient Data Bank. The NSP and energy intakes were calculated from the weights and types of foods consumed.

The cellulose fraction of NSP in Mexican foods was not determined in the NSP composition studies (Sánchez-Castillo et al. 1994c, 1995) and the reported glucose values included cellulose. To compare our dietary data with international studies we required estimates for cellulose and for non-cellulosic glucose fractions. These were obtained using international data (Englyst et al. 1988, 1989; Hudson \& Englyst, 1995) on the proportion of cellulose and glucose in similar foods.

\section{Validation of the dietary data}

The $24 \mathrm{~h}$ dietary recall method tends to lead to bias due to under-reporting of energy intake especially in obese subjects (Bingham, 1991) but the proportional bias is believed to be similar for each of the macronutrient components of energy. The extent of under-reporting of intakes was assessed using the energy intake (EI): BMR ratio. Energy intake, for subjects in energy balance, is equal to the sum of the basal metabolism, dietary thermogenesis and energy expended in physical activity. This sum when divided by the BMR is called the physical activity level (PAL; James \& Schofield, 1990). Thus, we may use the EI:BMR ratio as an estimate of PAL. BMR was predicted from age and weight (Schofield et al. 1985; World Health Organization, 1985). A threshold value of EI : BMR $(\mathrm{PAL})=1.01$ was used to indicate where under-reporting had occurred, as recommended by Goldberg $e t$ al. (1991). The use of a threshold such as this is intended to reduce bias so that subjects who satisfy the criterion provide data which is considered more representative of the group. Checks on the included and excluded subjects failed to show consistent differences between them so it was concluded that comparisons between groups were not markedly affected by those excluded.

\section{Calculations and statistical methods}

The NSP intake from each food was estimated by multiplying the portion size by its NSP content. The NSP intake was then calculated by summing all foods which made up an individual's daily intake. Unweighted means of the three $1 \mathrm{~d}$ measurements of NSP intake were calculated for each subject. Subjects were classified by age into two age bands, up to 30 years (young) and over 30 years (older). Thus there were eight groups in all, formed by combinations of the three factors: community, sex and age. The effects of these factors on the intake and composition of the NSP were investigated through ANOVA techniques for unbalanced data and generalized linear models using the statistical analysis package Genstat 5 (Genstat 5 Committee, 1987). Unless otherwise stated significance tests were 
performed at the $P=0.05$ probability level. Between- and within-subject components of variance for NSP intake and some of the NSP fractions were determined assuming no autocorrelation effects and are expressed as coefficients of variation. These components were used to check if $3 \mathrm{~d}$ was long enough for monitoring food intake.

\section{Standardizing intakes}

Generally speaking, heavier individuals have greater intakes than lighter ones. Tables of intake of energy, NSP, and components of NSP will therefore show a somewhat repetitive story determined in part by body weight. Thus, for example, we may expect for all constituents that intake is greater for males than for females. Also when total intake is incorrectly reported then so will be most, or all, of the constituents. A clearer picture of the diet often emerges from scaling the data to allow assessment of relative changes. For energy and NSP data two forms of standardization are frequently used, namely, standardization by BMR and standardization by energy intake. Thus, for example, energy intake scaled by BMR (EI : BMR) is commonly used to reduce the effects on intake caused by weight differences while NSP scaled by energy intake helps to highlight NSP-rich diets. The NSP constituents can also be standardized by total NSP intake or by some component of that intake. In practice this normally takes the trivial form of expressing constituents as a proportion of the whole, e.g. cellulose intake expressed as a proportion of insoluble NSP intake. We present both actual intakes and standardized intakes.

\section{RESULTS}

General characteristics of subjects

Table 1 shows the general characteristics of the subjects. The rural group were on average 6 years younger than the urban group. The men were approximately $10 \mathrm{~kg}$ heavier than the women and the women in the urban group were about $6 \mathrm{~kg}$ heavier than those in the rural community. Some of the weight differences were caused by height differences, the urban group being on average about $25 \mathrm{~mm}$ taller than the rural group. The sex difference in body weight disappeared when the weights were expressed as BMI but the urban group had a higher BMI than the rural group ( 26.1 v. 24.6), this difference being statistically significant $(P<0.05)$. The women carried on average over $10 \%$ more fat than the men and the urban group some $4.5 \%$ more fat than the rural group.

Table 1. Age, height, weight, BMI, percentage fatness and estimated BMR of rural and urban Mexican subjects tabulated by sex, community and age

(Mean values and standard deviations)

\begin{tabular}{|c|c|c|c|c|c|c|c|c|c|c|c|c|c|}
\hline \multirow[b]{2}{*}{ Subjects } & \multirow[b]{2}{*}{$n$} & \multicolumn{2}{|c|}{$\begin{array}{c}\text { Age } \\
\text { (years) }\end{array}$} & \multicolumn{2}{|c|}{$\begin{array}{l}\text { Height } \\
\text { (m) }\end{array}$} & \multicolumn{2}{|c|}{$\begin{array}{c}\text { Weight } \\
\text { (kg) }\end{array}$} & \multicolumn{2}{|c|}{$\begin{array}{c}\text { BMI } \\
\left(\mathrm{kg} / \mathrm{m}^{2}\right)\end{array}$} & \multicolumn{2}{|c|}{$\begin{array}{c}\text { Fatness } \\
(\%)\end{array}$} & \multicolumn{2}{|c|}{$\begin{array}{c}\text { BMR } \\
(\mathrm{MJ} / \mathrm{d})\end{array}$} \\
\hline & & Mean & SD & Mean & SD & Mean & SD & Mean & SD & Mean & SD & Mean & SD \\
\hline Men: Rural & 23 & 35.7 & 11.0 & 1.63 & 0.06 & 67.8 & 8.4 & 25.6 & 3.4 & $22 \cdot 1$ & 4.7 & 7.0 & 0.55 \\
\hline Urban & 19 & 39.3 & 15.4 & 1.67 & 0.07 & 69.6 & $10 \cdot 5$ & $25 \cdot 1$ & 3.7 & $25 \cdot 3$ & 6.6 & 6.94 & 0.55 \\
\hline$<30$ years & 16 & \multicolumn{2}{|c|}{$25 \cdot 1$} & 1.66 & 0.06 & 65.9 & 8.7 & 23.9 & 3.6 & $20 \cdot 1$ & 4.9 & 7.06 & 0.56 \\
\hline$>30$ years & 26 & \multicolumn{2}{|c|}{44.9} & 1.64 & 0.07 & 70.3 & 9.5 & 26.2 & 3.2 & 25.6 & $5 \cdot 3$ & 6.92 & 0.54 \\
\hline Women: Rural & 55 & $32 \cdot 1$ & 11.7 & 1.51 & 0.06 & 54.7 & 11.0 & $24 \cdot 1$ & $5 \cdot 3$ & 31.2 & 6.8 & $5 \cdot 38$ & 0.54 \\
\hline Urban & 57 & 38.5 & $11 \cdot 0$ & 1.53 & 0.06 & 61.8 & 11.9 & $26 \cdot 4$ & $4 \cdot 7$ & $36 \cdot 0$ & 4.9 & 5.71 & 0.49 \\
\hline$<30$ years & 51 & \multicolumn{2}{|c|}{$25 \cdot 3$} & 1.53 & 0.05 & 52.8 & $8 \cdot 5$ & $22 \cdot 6$ & $3 \cdot 3$ & 29.6 & $5 \cdot 5$ & $5 \cdot 33$ & 0.52 \\
\hline$>30$ years & 61 & \multicolumn{2}{|c|}{43.8} & 1.51 & 0.06 & 62.9 & 12.5 & 27.5 & $5 \cdot 3$ & 37.0 & 4.9 & 5.73 & 0.49 \\
\hline
\end{tabular}




\section{Validating intakes}

The PAL values were estimated by the EI:BMR ratio and are displayed in Table 2 . The cut-off value of 1.01 for specifying under-reporting allowed for both between- and withinsubject variability in intake and BMR, and is the lowest reported value likely to be compatible with the true intake of an individual in a population with a mean PAL of 1.55 when intake is measured over a $3 \mathrm{~d}$ period. Tables $3-10$ are based on only those individuals with a PAL value greater than 1.01 .

\section{Dietary energy}

Table 3 shows the estimated dietary energy intakes for both communities and sexes. As expected, a highly statistically significant difference in dietary energy was found between the sexes $(P<0.001)$ with men eating more than women. There was no significant difference in energy intake between the two communities or between the age groups. No significant differences in PAL were observed between the eight groups.

\section{NSP: soluble and insoluble}

The average daily intake of total NSP was $17.4 \mathrm{~g}$ (Table 4 ) and about $41 \%$ of this was soluble. Intake by males was greater than that by females $(19.8 v .16 .5 \mathrm{~g})$ reflecting the greater food intake of males. The rural group had a higher intake than the urban group $(18.6 v .16 \cdot 2 \mathrm{~g})$. Much of the difference between the intakes of the two communities and the two sexes was attributable to a very high intake by young rural males (mean $26.9 \mathrm{~g}$ ), older males having an intake $(17.0 \mathrm{~g})$ similar to that of the women.

In comparing the soluble and insoluble NSP intakes with the total, it should be noted that about $0.5 \mathrm{~g} / \mathrm{d}$ or $3 \%$ is associated with foods for which no information on the division between soluble and insoluble NSP was available. No attempt was made to guess appropriate figures for these small contributors so the sum of the soluble and insoluble fractions is slightly less than the total NSP value. Intakes of both soluble and insoluble NSP reflected the total NSP. Intakes of both fractions by older men were similar to those of older women whereas intakes for young men were approximately $42 \%$ higher than those for young women. However, although the intakes of both soluble and insoluble NSP were highest for the rural group, the rural-urban difference was greater for soluble intakes $(1.59 \mathrm{~g} / \mathrm{d})$ than for insoluble intakes (difference $0.84 \mathrm{~g} / \mathrm{d}$ ).

Table 2. Distribution (\%) of rural and urban Mexican subjects with different estimated physical activity levels (PAL; energy intake/estimated BMR) for each combination of community and sex (all subjects)

\begin{tabular}{lcccrr}
\hline & \multicolumn{2}{c}{ Men } & \multicolumn{2}{c}{ Women } \\
\cline { 2 - 4 } PAL & Rural & Urban & & Rural & Urban \\
\hline$<0.75$ & 4 & 5 & 9 & 0 \\
$<0.75-1.00$ & 13 & 5 & 4 & 25 \\
$1.00-1.25$ & 48 & 26 & 37 & 37 \\
$1.25-1.50$ & 17 & 37 & 22 & 21 \\
$1.50-1.75$ & 17 & 26 & 28 & 18 \\
\hline
\end{tabular}


Table 3. The mean energy intake and estimated physical activity level (PAL)* tabulated by community, sex and age for rural and urban Mexican subjects with PAL $>1.01$

\begin{tabular}{|c|c|c|c|}
\hline Subjects & $n$ & $\begin{array}{c}\text { Energy intake } \\
(\mathrm{MJ} / \mathrm{d})\end{array}$ & PAL \\
\hline Men: Rural & 18 & 9.35 & 1.31 \\
\hline Urban & 17 & $10 \cdot 14$ & 1.44 \\
\hline$<30$ years & 15 & 9.96 & 1.40 \\
\hline$>30$ years & 20 & 9.57 & $1 \cdot 35$ \\
\hline Average SEM & & 0.46 & 0.074 \\
\hline Women: Rural & 48 & $7 \cdot 37$ & 1.39 \\
\hline Urban & 43 & 7.79 & 1.34 \\
\hline$<30$ years & 44 & 7.50 & 1.41 \\
\hline$>30$ years & 47 & 7.63 & 1.32 \\
\hline Average SEM & & 0.30 & 0.049 \\
\hline Significance $\dagger$ & & $\mathbf{S}$ & - \\
\hline
\end{tabular}

$S$, sex effect.

*PAL = energy intake/estimated BMR.

†Entries indicate effects which are statistically significant at the $P=0.05$ probability level.

Energy standardized intakes were similar for both sexes but were much higher in the rural than in the urban community (Table 5). Even after standardization the effect of age on intake differed between the two sexes but then the difference was explained mostly by a low mean for the older males $(1.74 \mathrm{~g} / \mathrm{MJ})$.

Also shown in Table 5 are the means for soluble NSP expressed as a proportion of the total. For this proportion there was no influence of either sex or age but it was greater in the diets of the rural community than in those of the urban community.

Table 4. Mean intake of total NSP, soluble and insoluble NSP tabulated by community, sex and age for rural and urban Mexican subjects with physical activity levels $(P A L)^{*}>1.01$

\begin{tabular}{|c|c|c|c|}
\hline \multirow[b]{2}{*}{ Subjects } & \multicolumn{3}{|c|}{ Non-starch polysaccharides (g/d) } \\
\hline & Total & Soluble & Insoluble \\
\hline Men: Rural & $21 \cdot 81$ & 8.84 & 12.40 \\
\hline Urban & 17.72 & $6 \cdot 67$ & $10 \cdot 46$ \\
\hline$<30$ years & $23 \cdot 62$ & $9 \cdot 20$ & 13.84 \\
\hline$>30$ years & 16.98 & $6 \cdot 73$ & 9.67 \\
\hline Average SEM & 1.40 & 0.62 & 0.68 \\
\hline Women: Rural & $17 \cdot 32$ & $7 \cdot 32$ & 9.65 \\
\hline Urban & 15.64 & 5.93 & 9.20 \\
\hline$<30$ years & $16 \cdot 52$ & $6 \cdot 76$ & 9.32 \\
\hline$>30$ years & $16 \cdot 54$ & $6 \cdot 57$ & 9.55 \\
\hline Average SEM & 0.93 & 0.41 & 0.58 \\
\hline Significance & C,S,SA & C,S,SA & S,SA \\
\hline
\end{tabular}

$S$, sex effect; C, community effect; A, age effect; SA, sex $\times$ age interaction.

*PAL = energy intake/estimated BMR.

$\dagger$ Entries indicate effects which are statistically significant at the $P=0.05$ probability level. 
Table 5. Mean total, soluble and insoluble fractions of NSP intakes of rural and urban Mexican subjects standardized by estimated dietary energy intake, with theoretical physical activity levels $\left(P A L^{*}\right)$ used to scale up to estimated total NSP intakes

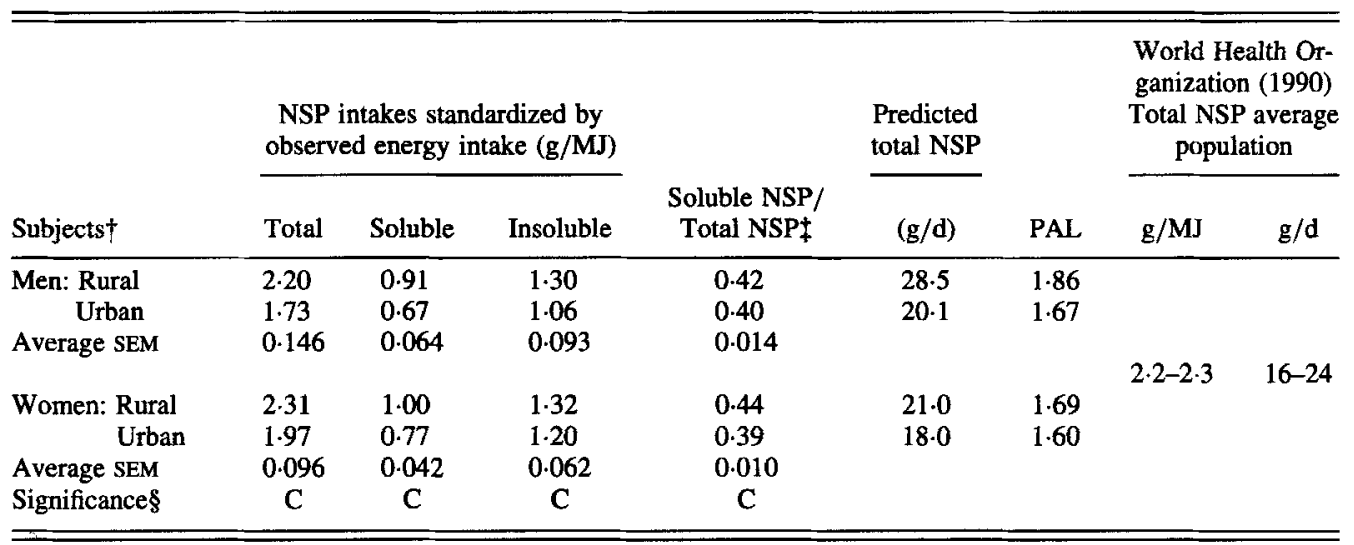

C, community effect.

*PAL = energy intake/estimated BMR.

† Subjects with PAL $>1.01$ only.

†The NSP was divided into soluble and insoluble fractions only.

$\S$ Entries indicate effects which are statistically significant at the $P=0.05$ probability level.

Table 6. Proportions of total NSP intake as cellulose (Cell), uronic acids (Ur Acid), arabinose (Ara), xylose (Xyl), glucose (Glu), mannose (Mann) and galactose (Galac) plus pentose sugars* and hexose sugars $\dagger$ tabulated by community and sex for rural and urban Mexican subjects

\begin{tabular}{|c|c|c|c|c|c|c|c|c|c|}
\hline Subjects & Cell & Ur Acid & Ara & Xyl & Glu & Mann & Galac & $\begin{array}{c}\text { Pentose } \\
\text { sugars }\end{array}$ & $\begin{array}{c}\text { Hexose } \\
\text { sugars }\end{array}$ \\
\hline Men: Rural & 0.23 & 0.16 & 0.18 & 0.19 & 0.105 & 0.035 & 0.084 & 0.37 & 0.22 \\
\hline Urban & 0.25 & 0.20 & 0.17 & 0.19 & 0.076 & 0.032 & 0.082 & 0.36 & 0.19 \\
\hline Average SEM & 0.006 & 0.013 & 0.006 & 0.008 & 0.006 & 0.002 & 0.002 & 0.012 & 0.008 \\
\hline Women: Rural & 0.22 & 0.18 & 0.17 & 0.18 & 0.099 & 0.037 & 0.086 & 0.36 & 0.22 \\
\hline Urban & 0.25 & 0.20 & 0.17 & 0.18 & 0.072 & 0.027 & 0.084 & 0.35 & 0.18 \\
\hline Average SEM & 0.004 & 0.010 & 0.004 & 0.005 & 0.004 & 0.001 & 0.001 & 0.009 & 0.006 \\
\hline Significance§ & $\mathrm{C}$ & C & - & - & $\mathrm{C}$ & C & - & - & C \\
\hline
\end{tabular}

C, community effect.

*Arabinose and xylose.

†Glucose, mannose, and galactose.

$\$$ Subjects with physical activity levels $(\mathrm{PAL})>1.01$ only. PAL $=$ energy intake/estimated $\mathrm{BMR}$.

$\S$ Entries indicate effects which are statistically significant at the $P=0.05$ probability level.

\section{Component sugars}

In all, seven sugars were assessed, namely, cellulosic glucose, uronic acid, arabinose, xylose, non-cellulosic glucose, galactose and mannose. It is convenient to group arabinose and xylose under the heading of pentose sugars and glucose, galactose and mannose under hexose sugars. The mean intakes of these sugars are presented in Table 6 as proportions of total NSP intake. A simple picture emerges: the diet for the urban community had approximately $3 \%$ more cellulose, $2 \%$ more uronic acid and $4 \%$ less hexose sugars than that for the rural community. There was no evidence for an effect of sex or age on these proportions. 
The proportions of pentose sugars in the diet were the same for all study groups and there was no effect on the relative amounts of arabinose and xylose. Among the hexose group the dominant effect was seen on the glucose estimated fraction, for of the $4 \%$ difference between the communities, some $3 \%$ was attributable to glucose alone. Values for variance components were determined for energy, total NSP, soluble NSP, insoluble NSP, NSP/energy and for the proportion of total NSP which was soluble. For each subject the variance of the mean intake over $k$ days is $V_{b}+V_{w} / k$ where $V_{b}$ and $V_{w}$ are the between-subject and within-subject variance components. In effect the second component corresponds to measurement error and will, for example, cause reductions in the intersubject correlation coefficients. We would like $\mathrm{V}_{\mathrm{w}} / \mathrm{kV}_{\mathrm{b}}$ to be small. However, in this investigation the ratios were generally in excess of 0.5 suggesting that a longer period of assessment (i.e. bigger values of $k$ ) would have been warranted.

\section{DISCUSSION}

Studies on intake based on dietary recall are beset with problems of variability and underreporting. In the present study it would have been advantageous to monitor the diet for up to a week and there was clearly a problem of under-reporting. The cut-off values recommended by Goldberg et al. (1991) allowed the sample to be reduced to those for whom reporting problems were considered not to be extreme. Tests to see whether the probability of rejecting a subject was influenced by community, sex, age or their weight proved negative so there was no evidence that rejecting the under-reporters introduced bias into the comparison of rural and urban results.

The original sample contained more women than men from both communities but this did not cause undue concern because the proportion of men was similar for the urban and the rural areas. However, in the rural group the majority of the women were aged 30 years or less whereas in the urban group the majority were aged over 30 years. It was therefore desirable to make comparisons with the possible effect of age taken into account.

It was expected that total intakes would vary between groups but that within communities the structure of the diet would not be greatly influenced by sex or age, since members of any family would tend to eat similar foods. The quantity of NSP consumed to some extent depends on the total food intake so there was advantage in standardizing the data by the calculated total dietary energy. When the total NSP intakes were standardized for energy intake and the components of NSP expressed as proportions of the total the effects of both sex and age disappeared but differences between the communities in NSP intakes remained. The extra intake of NSP by the rural community was also accompanied by differences in the intake of some sugars. Thus the intakes of hexose and pentose sugars as well as soluble NSP were higher in the rural group.

\section{Adjustment for under-reporting}

Bingham (1991) has estimated that the systematic bias in under-reporting $24 \mathrm{~h}$ recall data may amount to $20 \%$ but this value is likely to differ considerably between cultures. By expressing energy intake in relation to BMR the estimated PAL values provide an indicator of the degree of under-reporting. Thus, for the subjects to be in energy balance, a true intake corresponding to a PAL of 1.2 is compatible with complete bed rest and a PAL of 1.35 with extremely sedentary behaviour (Black $e t$ al. 1991). Yet in both rural and urban parts of Mexico the adults studied had to work for their living with few mechanized aids in the home and few had cars or ready access to transport. Their work patterns would be classified as of moderate activity. The Food and Agriculture Organization/World Health 
Organization/United Nations University report (World Health Organization, 1985) suggested that desirable intakes when engaged in light activity should amount to 1.55 PAL and for moderate activity should be 1.78 in men and 1.64 in women. James \& Schofield (1990), in an analysis of rural and urban activity patterns in developing countries, suggested a series of PAL values as approximate estimates for adults living in similar conditions to those in Mexico. If these theoretical values are used with the assumption that there was no selective under-reporting of the intake of particular foods, then Table 5 provides an alternative estimate of the NSP intakes of adults. Comparison of these estimates with Table 3 suggests a degree of under-reporting of the order reported by Bingham (1991).

The energy intakes of the rural groups were not higher than those of the respective urban groups although it might be expected that the work levels are higher for the former. However, Ferro-Luzzi (1996), in recent extensive analyses of physical activity in developing and developed countries, concluded that activity levels were not necessarily higher in developing countries and this feature may also prove to be true of suggested urban-rural differences. Thus rural women often confine their activities to the minimum household or agricultural tasks whereas urban women may be forced to undertake a fulltime job as well as looking after the household. New data on energy expenditure in rural and urban communities in developing countries is needed to resolve this issue.

For comparison, Table 5 also includes population goals for NSP intakes suggested by the World Health Organization (1990). Rural adults conformed with the suggested goals whereas the urban adults had an NSP/unit energy which had fallen below the population goal. The daily intakes we report are not strictly comparable with the population goals because the latter take account of the smaller intakes of children.

\section{Comparison of NSP intake with other countries}

Values for NSP intake from other countries presented by Cassidy et al. (1994) and the Commission of European Communities (1993) are displayed in Fig. 1. The reported intakes in Mexico are higher than those in European countries, Australia and USA but similar to those in India and Africa. When the Mexican and African data were adjusted for estimates of total energy intake, total NSP intakes for rural Mexican men and women were similar to those in Africa. NSP intakes in Indian men were comparable to those in urban Mexican men.

Urban and rural NSP intakes in Mexico can be compared with those reported in the International Agency for Research for Cancer study on large-bowel cancer in Scandinavia (International Agency for Research on Cancer Large Bowel Cancer Group, 1982). In Mexico the average intake of NSP is higher than those for the Scandinavian countries and if pulses and vegetables are not distinguished then most of this difference can be ascribed to greater intake of fruit in Mexico. Comparison of rural and urban groups within the three countries shows the NSP intake of urban groups to be less than that of the respective rural group (Table 7). However, the countries differ in how this reduction was achieved. In Denmark intake was reduced roughly in proportion for all groups of foods whereas for Finland the reduction was chiefly restricted to cereals and for Mexico to pulses.

Given the increasing interest in the selective protective effects of vegetable and fruit intakes on the development of cancers and coronary heart disease, studies on NSP intakes need to include careful assessment of both the sources of NSP and the intake of a range of bioactive components which these NSP rich plant foods contain. NSP may then prove to be 


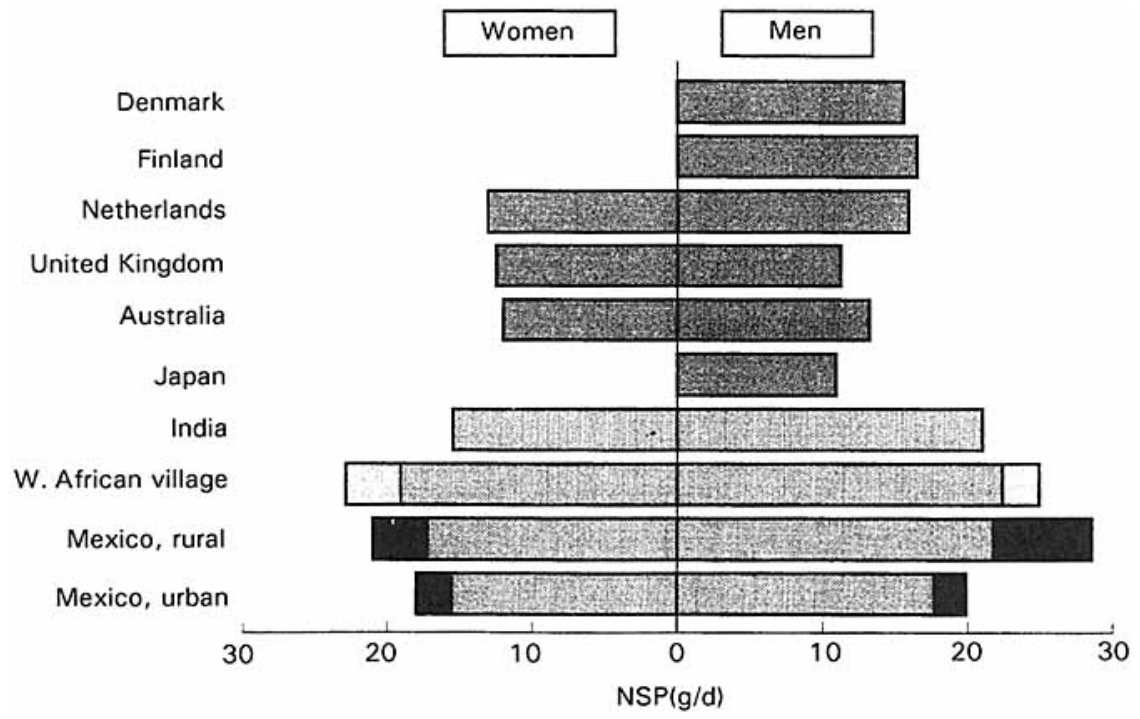

Fig. 1. NSP intakes in developed and developing countries. All values, except the African data (Commission of European Community, 1993) and the Mexican data (present study), are taken from Cassidy et al. (1994). The African data, where intakes from two meals supplied $80 \%$ of energy intake, were corrected to $100 \%$ of energy intake as indicated by (T); the expected NSP intake in Mexico is also given ( $\square$ ) as calculated from presumed physical activity level values given by James \& Schofield (1990) for adults living in developing countries.

Table 7. The total NSP intake and its sources in men from rural and urban communities in Scandinavia and Mexico

\begin{tabular}{|c|c|c|c|c|c|c|}
\hline \multirow[t]{2}{*}{ Country } & \multirow{2}{*}{$\begin{array}{c}\text { Total NSP } \\
\text { g/d }\end{array}$} & \multirow{2}{*}{$\frac{\text { Cereals }}{\mathrm{g} / \mathrm{d}(\%)}$} & \multirow{2}{*}{$\frac{\text { Pulses }}{\mathrm{g} / \mathrm{d}(\%)}$} & \multirow{2}{*}{$\frac{\text { Vegetables }}{\mathrm{g} / \mathrm{d}(\%)}$} & \multirow{2}{*}{$\frac{\text { Fruits }}{\mathrm{g} / \mathrm{d}(\%)}$} & \multirow{2}{*}{$\begin{array}{l}\text { Others } \\
\mathrm{g} / \mathrm{d}(\%)\end{array}$} \\
\hline & & & & & & \\
\hline \multicolumn{7}{|l|}{ Denmark } \\
\hline Rural & 18.0 & $10.4(58)$ & - & $5.0(28)$ & $2.0(11)$ & $0.5 \quad(3)$ \\
\hline Urban & $13 \cdot 2$ & $7.8(59)$ & - & $3.4(26)$ & $1.3(10)$ & $0.7 \quad(5)$ \\
\hline \multicolumn{7}{|l|}{ Finland } \\
\hline Rural & 18.4 & $13.4(73)$ & - & $3 \cdot 1(17)$ & $1 \cdot 1(6)$ & $0.7 \quad$ (4) \\
\hline Urban & 14.6 & $8.8(60)$ & - & $4 \cdot 2(29)$ & $1.0(7)$ & 0.6 (4) \\
\hline \multicolumn{7}{|c|}{ Mexico (present study) } \\
\hline Rural & 21.8 & $10.9(50)$ & $4.4(20)$ & 3.1 (14) & $3.5(16)$ & $0.02(0.1)$ \\
\hline Urban & 17.7 & $9.9(56)$ & $1.2(7)$ & $2.7(15)$ & $3.9(22)$ & $0.07(0.4)$ \\
\hline
\end{tabular}

a useful marker of the dietary intakes of plant foods whose principal benefits depend on their content of phytoprotectants.

The authors wish to thank Norma Limón and Jesús Flores from the Department of Rural Studies (INNSZ) for helping in the collection of data, and Helen Watt (RRI) and Karen Robertson (BioSS) for assistance with data computing and analysis. Royal Society of Chemistry/Crown copyright material from the Nutrient Databank and the Composition of Foods is used with the permission of the Royal Society of Chemistry and the Controller of Her Majesty's Stationery Office and with the agreement of the Minister of Agriculture, Fisheries and Food. We also thank the Nestlé Company (Mexico) for helping with the 
completion of this paper. Supported by: Scottish Office Agriculture, Environment and Fisheries Department and the British Council.

\section{REFERENCES}

Bingham, S. A. (1991). Limitations of the various methods for collecting dietary intake data. Annals of Nutrition and Metabolism 35, 117-127.

Black, A.E., Goldberg, G. R., Jebb, S. A., Livingstone, M. B. E., Cole, T. J. \& Prentice, A. M. (1991). Critical evaluation of energy intake data using fundamental principles of energy physiology: 2. Evaluating the results of published surveys. European Journal of Clinical Nutrition 45, 583-599.

Bobadilla, J. L., Frenk, J., Lozano, R., Frejka, T. \& Stern, C. (1993). The epidemiologic transition and health priorities. In Disease Control Priorities in Developing Countries, pp. 51-63 [D. T. Jamison, W. H. Mosley, A. R. Measham and J. L. Bobadilla, editors]. Oxford: Oxford University Press Inc. The World Bank.

Burkitt, D. P. (1971). Epidemiology of cancer of the colon and rectum. Cancer 28, 3-13.

Burkitt, D. P. (1972). Effect of dietary fibre on stools and transit times, and its role in the causation of disease. Lancet ii, 1408-1412.

Cassidy, A., Bingham, S. A. \& Cummings, J. H. (1994). Starch intake and colorectal cancer risk: an international comparison. British Journal of Cancer 69 937-942.

Commission of the European Communities, Directorate-General (1993). Science, Research and Development. Dietary Fibre Intakes in Europe [J. H. Cummings and F. Wenche, editors]. Luxembourg: Commission of the European Communities.

Cummings, J. H., Bingham, S. A., Heaton, K. W. \& Eastwood, M. A. (1992). Faecal weight, colon cancer risk and dietary intake of non-starch polysaccharides (dietary fibre). Gastroenterology 103, 1783-1789.

Durnin, J. V. G. A. \& Womersley, J. (1974). Body fat assessed from total body density and its estimation from skinfold thickness: measurements on 481 men and women aged from 16-72 years. British Joumal of Nutrition 32, 77-97.

Englyst, H. N., Bingham, S. A., Runswick, A., Collinson, E. \& Cummings, J. H. (1988). Dietary fibre (nonstarch polysaccharides) in fruit, vegetables and nuts. Journal of Human Nutrition and Dietetics 1, 247-286.

Englyst, H. N., Bingham, S. A., Runswick, S. A., Collinson, E. \& Cummings, J. H. (1989). Dietary fibre (nonstarch polysaccharides) in cereal products. Journal of Human Nutrition and Dietetics 2, 253-271.

Ferro-Luzzi, A. (1996). Obesity and physical activity. In Origins and Consequences of Obesity. Ciba Foundation Symposium no 201. Chichester: John Wiley.

Garrow, J. S. (1988). Obesity and Related Diseases. London: Churchill Livingstone.

Genstat 5 Committee (1987). The Genstat 5 Reference Manual. Oxford: Clarendon Press.

Goldberg, G. R., Black, A. E., Jebb, S. A., Cole, T. J., Murgatroyd, P. R., Coward, W. A. \& Prentice, A. M. (1991). Critical evaluation of energy intake using fundamental principles of energy physiology: 1. Derivation of cut-off limits to identify under-recording. European Journal of Clinical Nutrition 45, 569-581.

Goulder, T. J., Alberti, K. G. \& Jenkins, D. J. A. (1978). Effect of added fibre on the glucose and metabolic response to a mixed meal in normal and diabetic subjects. Diabetes Care 1, 351-355.

Heaton, K. W., Emmett, P. M., Symes, C. L. \& Braddon, F. E. M. (1993). An explanation for gallstones in normal-weight women: slow intestinal transit. Lancet 341, 8-10.

Hernández, M., Chávez, A. \& Bourges, H. (1980). Valor Nutritivo de los Alimentos Mexicanos. Tablas de Uso Práctico (Nutritional Value of Mexican Foods. Tables of Practical Use), 6th ed. Tlalpan, Mexico: Instituto Nacional de la Nutrición Salvador Zubirán.

Holland, B., Unwin, I. D. \& Buss, D. H. (1991a). Vegetables, Herbs and Spices. Fifth Supplement to McCance and Widdowson's The Composition of Foods, 4 th ed. Cambridge: Royal Society of Chemistry and Ministry of Agriculture, Fisheries and Food.

Holland, B., Unwin, I. D. \& Buss, D. H. (1991b). Fruits and Nuts. First Supplement to McCance and Widdowson's The Composition of Foods 5th ed. Cambridge: Royal Society of Chemistry and Ministry of Agriculture, Fisheries and Food.

Holland, B., Welch, A. A., Unwin, I. D., Buss, D. H., Paul, A. A. \& Southgate, D. A. T. (1991c). McCance and Widdowson's The Composition of Foods, 5th ed. Cambridge: Royal Society of Chemistry and Ministry of Agriculture, Fisheries and Food.

Hudson, G. \& Englyst, H. (1995). Dietary intakes of starch and non-starch polysaccharides in a west African village. British Journal of Nutrition 73, 655-666.

International Agency for Research on Cancer Large Bowel Cancer Group (1982). Second IARC international collaborative study on diet and large bowel cancer in Denmark and Finland. Nutrition and Cancer 4, 3-79.

James, W. P. T. \& Schofield, E. C. (1990). Human Energy Requirements. Oxford, New York, Tokyo: Oxford Medical Publications, Oxford University Press.

Jenkins, D. J. A. (1988). Carbohydrates: dietary fibre. In Modern Nutrition in Health and Disease, 7 th ed., pp. 52-71 [M. Shils and V. Young, editors]. Philadelphia: Lea and Febiger. 
Kromhout, D., Bosschieter, E. B. \& de Lezenne Coulander C. (1982). Dietary fibre and 10-year mortality from coronary heart disease, cancer and all causes: the Zutphen study. Lancet ii, 518-522.

Kushi, L. H., Lew, R. A., Stare, F. J., Ellison, C.R., el- Lozy, M., Bourke, G., Daly, L., Graham, Y., Hickey, N., Mulcahy, R. \& Kevaney, J. (1985). Diet and 20-year mortality from coronary heart disease: the Ireland Boston Diet-Heart Study. New England Journal of Medicine 312, 811-818.

Morris, J. N., Marr, J. W. \& Clayton, D. G. (1977). Diet and heart: a postscript. British Medical Journal 2, 13071314.

Sánchez-Castillo, C. P., Bourges, H., Romero Keith, J., Graizbord, B. \& Gross R. (editors) (1994a). Nutritional Challenges in Urban Areas in Latin America. A Biomedical and Social Sciences Approach. Archivos Latinoamericanos de Nutricion 44, Suppl. 2.

Sanchez-Castillo, C. P., Dewey, P., Bourges, H. \& James, W. P. T. (1994b). Dietary fibre, what it is and how it is measured. Archivos Latinamericanos de Nutricion 44, 68-75.

Sánchez-Castillo, C. P., Dewey, P. J. S., Solano, M. de L., Finney, S. \& James, W. P. T. (1995). The dietary fibre content (non-starch polysaccharides) of Mexican fruits and vegetables: preliminary data. Journal of Food Composition and Analysis 8, 284-294.

Sánchez-Castillo, C. P., Dewey, P. J. S., Solano, M. de L., Tucker, M. \& James, W. P. T. (1994c). The nonstarch polysaccharides (NSP) in Mexican pulses and cereal products. Journal of Food Composition and Analysis 7, 260-281.

Sánchez-Castillo, C. P., Graizbord, B., Casey, C., Garrocho, C. F. \& Rodríguez, F. (1989). Consideraciones sobre la urbanizacion en la dieta, nutrición y estado de salud: definición de comunidades urbanas y rurales en el Estado de Mexico (Considerations on urbanization, nutrition and health status: definition of urban and rural communities in the State of Mexico). Revista Chilena de Nutrición 17, 46-54.

Schofield, W. N., Schofield, C. \& James, W. P. T. (1985). Basal metabolic rate. Human Nutrition: Clinical Nutrition 39C, Suppl. 1, 5-41.

Secretaría de Salud, Subsecretaría de Coordinacion y Desarrollo, Dirección General de Estadística, Informática y Evaluacion (1991). Mortalidad (Mortality). Mexico: Secretaría de Salud.

Villalobos, J. J., Vargas, F., Villareal, H. A. Olivera, M. A., Anzures, M. E., Rodríguez, L., Boom, R., Olaeta, R. Pérez Huacuja, R., Santoyo, R., Pelaez, M., Esquivel, F. \& Contreras, R. (1990). Estudio prospectivo de 10 años de cancer del aparato digestivo (Ten-year prospective study of cancer of the digestive system). Revista de Gastroenterología de Mexico 55, 17-24.

Vinik, A. I. \& Jenkins, D. J. A. (1978). Dietary fibre in management of diabetes. Diabetes Care 1, 351-355.

Weinsier, R. L., Johnston, M. H., Doleys, D. M. \& Bacon, J. A. (1982). Dietary management of obesity: evaluation of the time-energy displacement diet in terms of its efficacy and nutritional adequacy for long-term weight control. British Journal of Nutrition 47, 367.

Willett, W. (1989). The search for causes of breast and colon cancer. Nature 338, 389-394.

World Health Organization (1985). Energy and Protein Requirements. Report of a Joint FAO/WHO/UNU Expert Consultation. Technical Report Series no. 724. Geneva: WHO.

World Health Organization (1990). Diet, Nutrition and the Prevention of Chronic Diseases. Technical Report Series no. 797. Geneva: WHO. 